\title{
Morphological Characterization of Different Genotype of Brinjal (Solanum Melongena)
}

\author{
Neetu Nand, Anupam Adarsh*, Amit Kumar, S. Akhtar, \\ Randhir Kumar and Pankaj Kumar Ray
}

Department of Horticulture (Vegetable and Floriculture), Bihar Agricultural University, Sabour-813210, Bhagalpur, Bihar, India

*Corresponding author

\section{A B S T R A C T}

Genetic divergence among 30 eggplant (Solanum melongena L.) genotypes was estimated using Mahalanobis $\mathrm{D}^{2}$ Statistics. The 30 genotypes were grouped into six distinct clusters. Among the different clusters, cluster III consisted maximum number of genotypes ( 8 genotypes) followed by cluster I and VI (5 genotypes), cluster II, IV and V contained (4

\section{Keywords}

Eggplant, Cluster analysis, $\mathrm{D}^{2}$

Statistics, Principle component,

Dendogram

\section{Article Info}

Accepted: 16 December 2017 Available Online: 10 January 2018 genotypes). The highest intra-cluster distance was recorded for cluster I (1250.024) followed by cluster II (1217.052) and the lowest intra-cluster distance was recorded for cluster-V (389.277). However, the highest inter-cluster distance was observed between cluster IV and V (6815.521) while it was lowest between cluster III and IV (1149.46). The highest contribution in manifestation of genetic divergence was exhibited by days to first flowering, followed by days to $50 \%$ flowering, fruit set percentage and fruit girth. The cluster III showed moderate mean values for all the characters under study except for number of primary branches. Cluster II had highest mean values for number of primary branches and fruit set percentage, Cluster I showed higher mean values for number of fruits per plant, Cluster IV showed higher mean values for plant height and fruit yield per plant, Cluster V showed higher mean values for fruit length, petiole length and test weight while cluster VI had higher mean values for fruit weight, plant spread, days to first flowering, days to $50 \%$ flowering, fruit girth, days to first harvest. Considering the genetic divergence, clustering pattern and mean performance of genotypes for fruit yield and contributing characters 9 genotypes comprising EC-467273, 71-19, Rajendra Baigan-2, Pusa purple long, JB-15, IC-89933, Pant Rituraj and Muktakeshi may be considered as elite genotypes and hybridization involving these genotypes are likely to give desirable segregants for yield and its components characters.

\section{Introduction}

Eggplant (Solanum melongena L.) or brinjal, worldwide known as aubergine or guinea squash, is one of the most popular and major vegetable crops in India and other parts of the world, belonging to the nightshade family Solanaceae. It is an often cross pollinated annual herbaceous plant, originated in India and shows secondary diversity in South East Asia (Haushna, 2009). Brinjal fruits are rich sources of minerals like calcium, magnesium, 
potassium, iron, zinc and copper. It is also a fair source of fatty acids and it is used for medicinal purposes in curing diabetes, asthma, cholera, bronchitis and diarrhoea. It is reported to stimulate the intra-peptic metabolism of blood cholesterol. Leaf and fruit, fresh or dry produce marked drop in blood cholesterol level. The hypo cholesterolemic action is attributed to the presence of polyunsaturated fatty acids (lionleic and linolenic) which are present in flesh and seeds of the fruit in higher amount (65.1 \%) (Timmapur, 2007). The multivariate analysis provides valuable information on the extent of variation present in the crop under improvement and helps a plant breeder in choosing desirable parents for breeding programme (Singh, et al., 2006). Also inclusion of genetically diverse parents in any breeding programme is essential to generate new variability and desirable recombinants. Involvement of genetically diverse parents is essential to generate new variability and to look for desirable recombinants with respect to enhanced yield, quality and resistance to several important diseases. Genetically diverse parents are likely to segregates and or to produce high heterotic crosses. More diverse the parents, greater are the chances of obtaining high heterotic $F_{1} s$ and broad spectrum of variability in segregating generations (Arunachalam, 1984). Cluster analysis and PC (principal component) analysis are the important genetic diversity measuring tools employed for exhibiting relative genetic differences among the genotype collection of various crop species. The aim of forming clusters and finding the intra and inter cluster divergence is to provide the base of selecting parents for a planned breeding programme.

\section{Materials and Methods}

The experimental material comprised of 30 genotypes and the field experiment was conducted at Vegetable Research Farm, BAU,
Sabour, Bhagalpur in the kharif season during 2013-14. Each entry was sown at spacing of $60 \times 60 \mathrm{~cm}$ with three replications accommodating 12 seedlings in each plot. All the recommended cultural practices and plant protection measures were followed data were recorded for 12 characters viz., plant height $(\mathrm{cm})$, plant spread $(\mathrm{cm})$, number of primary branches, fruit set percentage, days to first flowering, days to $50 \%$ flowering, fruit length $(\mathrm{cm})$, fruit girth $(\mathrm{cm})$, fruit weight $(\mathrm{gm})$, test weight $(\mathrm{gm})$, petiole length $(\mathrm{cm})$, fruit yield per plant $(\mathrm{Kg})$ and twelve quality parameters like leaf blade colour, leaf pubescence, presence of prickles on upper leaf, calyx colour, corolla colour, plant growth habit, fruit pedicel prickles, calyx spininess, fruit shape, fruit colour, seediness and seed colour. Cluster and PC analysis of 30 brinjal genotypes based on yield and its 12 component traits to assess the magnitude of genetic variation was performed by using statistical software Windostat version 8.6 from Indostat services. Genetic diversity is estimated using Mahalanobis D2 statistics. After this a method (Ward's minimum variance method) suggested by Ward (1963) is used for cluster formation.

\section{Results and Discussion}

The 30 genotypes taken for genetic divergence analysis and clustered for 14 quantitative characters into different group based on Mahalanobis $\mathrm{D}^{2}$ statistics. On the basis of $\mathrm{D}^{2}$ values, the 30 genotypes were cluster into six clusters, presented in Table 1. Among the different clusters, cluster III consisted maximum number of genotypes (8 genotypes) followed by cluster I and VI (5 genotypes), cluster II, IV and V contained (4 genotypes). Similar type of findings was reported by Goloni et al., (2007). The inter and intra cluster distance D values which shows the index of genetic diversity among clusters were computed for 14 characters. A perusal of Table 2 shows that the highest intra-cluster 
distance was recorded for cluster I (1250.024) followed by cluster II (1217.052) while cluster $\mathrm{V}$ recorded minimum intra-cluster distance of 389.27. Similar types of results were obtained by Muniappan et al., (2010). The inter-cluster distance ranged from 1149.46 to 6815.521 between cluster III and IV and cluster IV and $\mathrm{V}$ respectively. However, the highest intercluster distance was observed between cluster IV and V (6815.521) followed by cluster II and V (4230.82), cluster IV and VI (4064.033) cluster III and V (3869.051) and cluster I and V (3394.939) indicating wider genetic diversity among the genotypes between these groups. Similar types of findings were reported by Mohanty and Prusuti (2001), Jagtar Singh et al., (2006).

A comparison of the mean values of different clusters for 14 characters, presented in Table 3 and it was observed that Cluster II had highest mean values for number of primary branches (5.301) and fruit set percentage (51.527) and lowest mean values for days to first harvest (92.801), Cluster I showed higher mean values for number of fruits per plant (12.783) and lowest mean values for fruit weight (92.178), plant spread (65.196) and fruit yield per plant (1.168). Cluster IV showed higher mean values for plant height (71.517), fruit yield per plant (1.775) and lower mean values for test weight (4.826), Cluster V showed higher mean values for fruit length (27.503), petiole length (3.503), test weight (5.650) and lower mean values for plant height (51.003), days to first flowering (37.00), days to $50 \%$ flowering (50.00), fruit girth (9.317), while cluster VI had higher mean values for fruit weight (210.980), plant spread (92.250), days to first flowering (50.00), days to $50 \%$ flowering (60.00), fruit girth (20.933), days to first harvest (112.00) and had showed lower mean values for fruit length (8.503), petiole length (2.750), number of fruits per plant (7.503) and fruit set percentage (32.640). The similar result was reported by Das et al., (2010),
Munshi et al., (2011). High cluster mean for most of the yield contributing traits coupled with inter cluster distance was found in cluster $\mathrm{VI}$ and cluster $\mathrm{V}$ which indicate the possibility of obtaining high heterotic vigour and selection of superior segregants by inter crossing genotypes from these clusters. In the present investigation the highest contribution in manifestation of genetic divergence was exhibited by days to first flowering, followed by days to $50 \%$ flowering, fruit set percentage, fruit girth, plant spread, test weight and number of primary branches. Fruit yield, days to first harvest, petiole length and plant height contributing least towards genetic divergence, presented in Table 4. The importance of fruit girth in genetic divergence of brinjal had been observed by Prabakaran (2010). Similar conclusions were drawn by Tambe et al., (1993); Yadav et al., (1996); Samaik and Verma (1999); Sharma and Maurya (2004); Chandrasekhar et al., (2012) and Goloni et al., (2007). The PCA of the fourteen traits in 30 brinjal genotypes is shown in Table 5. The first four PCs having Eigen values greater than one accounted for $88.04 \%$ of total variation amongst brinjal genotypes. Moreover, the first 5 PCs contributed $93.41 \%$ of the total variation with proportionate contribution values of 39.52, $24.72,15.49,8.30$ and $5.38 \%$ respectively. Two dimensional ordinations of 30 brinjal genotypes on PC axis 1 and 2 are represented in Figure 1, which revealed scattered diagram of genotypic distribution pattern on axis. The first PC has positive association with fruit length, days to $1^{\text {st }}$ flowering, days to $1^{\text {st }}$ harvest, fruit set\% and fruit girth while negative association with plant spread, test weight and number of primary branches. The second PC has positive association with fruit weight, days to $1^{\text {st }}$ flowering and fruit girth while negative association with plant height, number of fruits per plant and days to $50 \%$ flowering. 
Table.1 Composition of clusters based on Ward's minimum variance of 30 genotypes

\begin{tabular}{|l|c|l|}
\multicolumn{1}{|c|}{ Clusters } & $\begin{array}{c}\text { Number of } \\
\text { genotypes }\end{array}$ & \multicolumn{1}{c|}{ Cluster members } \\
\hline Cluster I & 5 & JB-9, EC-384970, KS-331, Punjab Sadabahar, Nurkee \\
\hline Cluster II & 4 & Swarna Mani, Muktakeshi, IC-261802, JB-15 \\
\hline Cluster III & 8 & $\begin{array}{l}\text { IVBL-10, EC-305105, JB-8, IC-354666, IC-90149, IC- } \\
\text { 215018, IC-89910-K, IC-112341 }\end{array}$ \\
\hline Cluster IV & 4 & EC-169084, EC-467273, EC-305013, IC-90933 \\
\hline Cluster V & 4 & 71-19, Rajendra Baigan-2,Pusa Purple Long, PB-67 \\
\hline Cluster VI & 5 & IC-89837, IC-89933, PB-70, Pant Rituraj, Pusa Shyamla \\
\hline
\end{tabular}

Table.2 Average of intra (diagonal) and inter cluster distance

\begin{tabular}{|l|c|c|r|r|r|r|}
\multicolumn{7}{|c|}{ Euclidean $^{2}$ : Cluster Distances : Ward } \\
\hline & $\begin{array}{c}1 \\
\text { Cluster }\end{array}$ & $\begin{array}{c}\mathbf{2} \\
\text { Cluster }\end{array}$ & $\begin{array}{c}\text { C } \\
\text { Cluster }\end{array}$ & $\begin{array}{c}\text { Cluster } \\
\text { Cluster }\end{array}$ & 5 Cluster \\
\hline 1 Cluster & 1250.024 & 2036.938 & 1707.588 & 1936.803 & 3394.939 & 2357.767 \\
\hline 2 Cluster & & 1217.052 & 2082.03 & 2342.741 & 4230.82 & 2377.791 \\
\hline 3 Cluster & & & 553.821 & 1149.46 & 3869.051 & 1905.471 \\
\hline 4 Cluster & & & & 420.647 & 6815.521 & 4064.033 \\
\hline 5 Cluster & & & & & 389.277 & 1223.943 \\
\hline 6 Cluster & & & & & & 740.226 \\
\hline
\end{tabular}

Table.3 Mean values of six cluster for 14 morphological characters in brinjal genotypes

\begin{tabular}{|l|c|c|c|c|c|c|}
\multicolumn{1}{|c|}{ Characters } & $\begin{array}{c}\mathbf{1} \\
\text { Cluster }\end{array}$ & $\begin{array}{c}\mathbf{2} \\
\text { Cluster }\end{array}$ & $\begin{array}{c}\mathbf{3} \\
\text { Cluster }\end{array}$ & $\begin{array}{c}\mathbf{4} \\
\text { Cluster }\end{array}$ & $\begin{array}{c}\mathbf{5} \\
\text { Cluster }\end{array}$ & $\begin{array}{c}\mathbf{6} \\
\text { Cluster }\end{array}$ \\
\hline Plant height (cm) & 11.127 & 14.802 & 20.380 & 16.079 & 27.503 & 8.503 \\
\hline Plant spread (cm) & 92.178 & 114.199 & 133.723 & 167.067 & 106.413 & 210.980 \\
\hline $\begin{array}{l}\text { No. of primary } \\
\text { branches }\end{array}$ & 12.783 & 13.382 & 11.522 & 9.468 & 12.027 & 7.503 \\
\hline Fruit set \% & 2.753 & 2.753 & 3.038 & 3.189 & 3.503 & 2.750 \\
\hline Days to 1st flowering & 62.130 & 70.271 & 68.370 & 71.517 & 51.003 & 60.247 \\
\hline Days to 50 \% flowering & 65.196 & 76.533 & 68.067 & 73.720 & 68.003 & 92.250 \\
\hline Petiole length (cm) & 4.500 & 5.301 & 4.041 & 4.444 & 4.500 & 4.500 \\
\hline Days to 1 st harvest & 43.125 & 40.001 & 47.143 & 44.375 & 37.000 & 50.000 \\
\hline Fruit length (cm) & 53.751 & 50.003 & 57.573 & 55.375 & 50.000 & 60.000 \\
\hline Fruit girth (cm) & 96.877 & 92.801 & 103.143 & 101.126 & 96.000 & 112.000 \\
\hline No. of fruits/plant & 4.831 & 5.070 & 5.121 & 4.826 & 5.650 & 5.200 \\
\hline Fruit weight (g) & 1.168 & 1.523 & 1.522 & 1.775 & 1.330 & 1.517 \\
\hline Test weight (g) & 13.263 & 15.343 & 15.794 & 18.258 & 9.317 & 20.933 \\
\hline Fruit yield/ plant (Kg) & 49.757 & 51.527 & 45.397 & 38.977 & 42.050 & 32.640 \\
\hline
\end{tabular}


Table.4 Percentage contribution of each character towards total genetic divergence in 30 genotypes

\begin{tabular}{|l|c|c|}
\multicolumn{1}{|c|}{ Characters } & Times Ranked 1 & Contribution \% \\
\hline 1. Fruit length $(\mathrm{cm})$ & 0 & 0.00 \\
\hline 2. Fruit Weight $(\mathrm{gm})$ & 0 & 0.00 \\
\hline 3. fruits/ plant & 0 & 0.00 \\
\hline 4. Petiole length $(\mathrm{cm})$ & 1 & 0.23 \\
\hline 5. Plant height $(\mathrm{cm})$ & 1 & 0.23 \\
\hline 6. Plant spread $(\mathrm{cm})$ & 16 & 3.68 \\
\hline 7. primary branches & 12 & 2.76 \\
\hline 8. Days to 1st flowering & 202 & 46.44 \\
\hline 9. Days to 50\% flowering & 67 & 15.40 \\
\hline 10. Days to 1st harvest & 1 & 0.23 \\
\hline 11. Test weight $(\mathrm{gm})$ & 15 & 3.45 \\
\hline 12. Fruit yield/ plant $(\mathrm{Kg})$ & 5 & 1.15 \\
\hline 13. Fruit Girth $(\mathrm{cm})$ & 54 & 12.41 \\
\hline 14. Fruit Set $\%$ & 61 & 14.02 \\
\hline
\end{tabular}

Table.5 Principal component analysis for 14 traits in 30 brinjal genotypes

\begin{tabular}{|l|c|c|c|c|c|}
\hline $\begin{array}{l}\text { Eigene Value } \\
\text { (Root) }\end{array}$ & $\mathbf{1 ~ V e c t o r}$ & $\mathbf{2}$ Vector & $\mathbf{3}$ Vector & $\mathbf{4}$ Vector & $\mathbf{5}$ Vector \\
\hline \% Var. Exp. & $\mathbf{3 . 4 6 1}$ & $\mathbf{2 . 1 6 9}$ & $\mathbf{1 . 1 6 2}$ & $\mathbf{0 . 7 5 3}$ \\
\hline Cum. Var. Exp. & $\mathbf{3 9 . 5 2 3}$ & $\mathbf{2 4 . 7 2 4}$ & $\mathbf{1 5 . 4 9 1}$ & $\mathbf{8 . 3 0 3}$ & $\mathbf{5 . 3 7 9}$ \\
\hline Fruit length (cm) & 0.315 & 0.126 & 0.387 & 0.150 & 0.027 \\
\hline $\begin{array}{l}\text { Fruit Weight (gm) } \\
\text { fruits/ plant }\end{array}$ & -0.036 & 0.500 & 0.041 & -0.213 & 0.081 \\
\hline Petiole length (cm) & 0.146 & -0.428 & 0.253 & 0.019 & -0.181 \\
\hline Plant height (cm) & -0.165 & -0.224 & -0.293 & -0.078 & 0.788 \\
\hline Plant spread (cm) & -0.136 & -0.427 & 0.051 & 0.088 & -0.066 \\
\hline primary branches & -0.356 & 0.093 & -0.202 & 0.195 & -0.354 \\
\hline $\begin{array}{l}\text { Days to 1st } \\
\text { flowering }\end{array}$ & 0.385 & 0.108 & -0.097 & -0.036 & -0.045 \\
\hline $\begin{array}{l}\text { Days to 50\% } \\
\text { flowering }\end{array}$ & 0.181 & -0.256 & -0.146 & 0.003 & -0.022 \\
\hline Days to 1st harvest & 0.303 & 0.123 & -0.427 & -0.102 & 0.095 \\
\hline Test weight (gm) & -0.335 & -0.078 & -0.282 & -0.163 & -0.339 \\
\hline $\begin{array}{l}\text { Fruit yield/ plant } \\
\text { (Kg) }\end{array}$ & 0.006 & -0.162 & 0.122 & -0.851 & -0.116 \\
\hline Fruit Girth (cm) & 0.277 & 0.348 & -0.191 & -0.047 & -0.150 \\
\hline Fruit Set \% & 0.314 & -0.163 & -0.292 & -0.244 & -0.151 \\
\hline
\end{tabular}


Fig.1 Scattered diagram: two dimensional ordination of 30 brinjal genotypes based on PC (principal component) axis 1 and 2
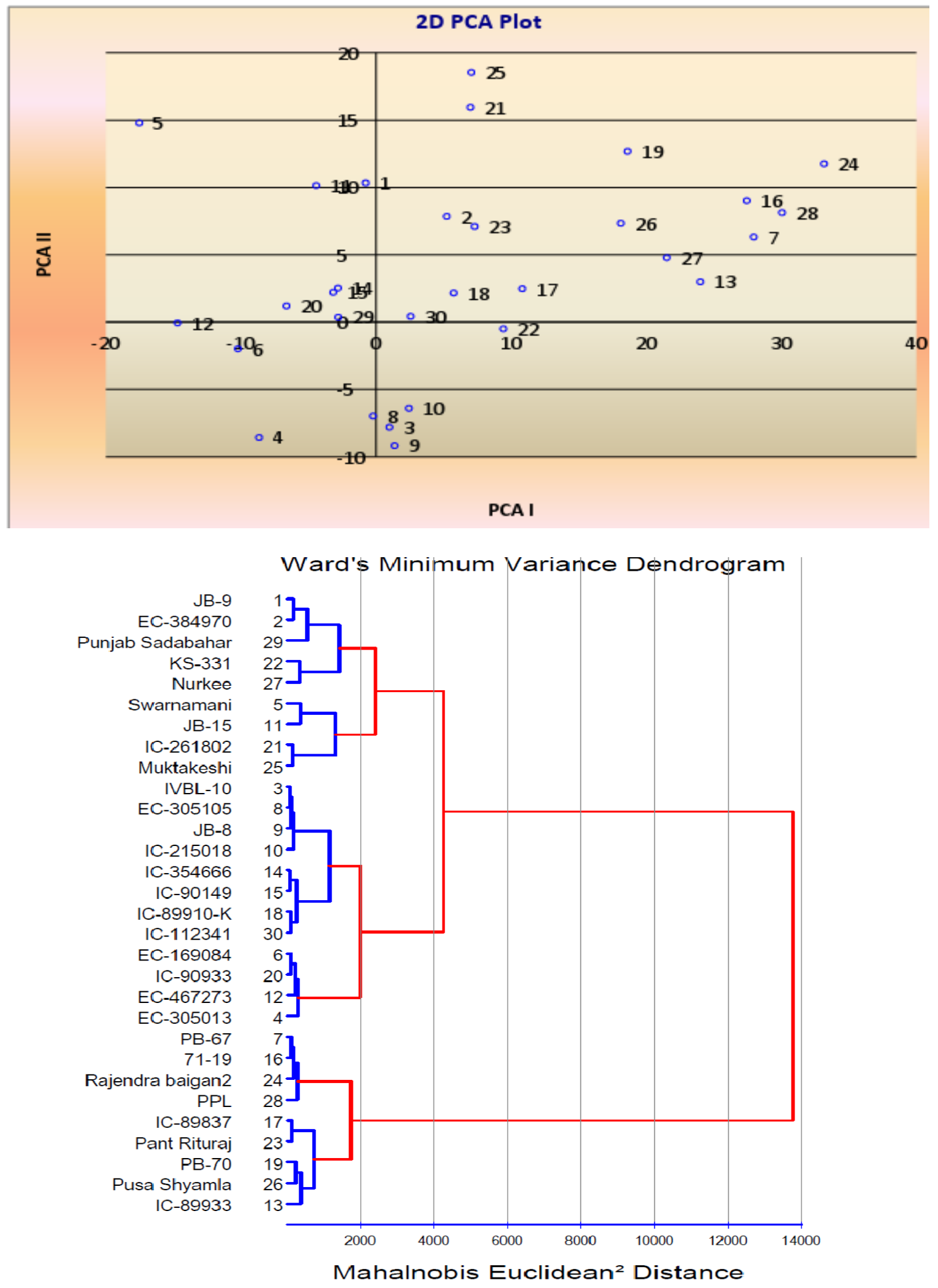


\section{D Editor Plot}

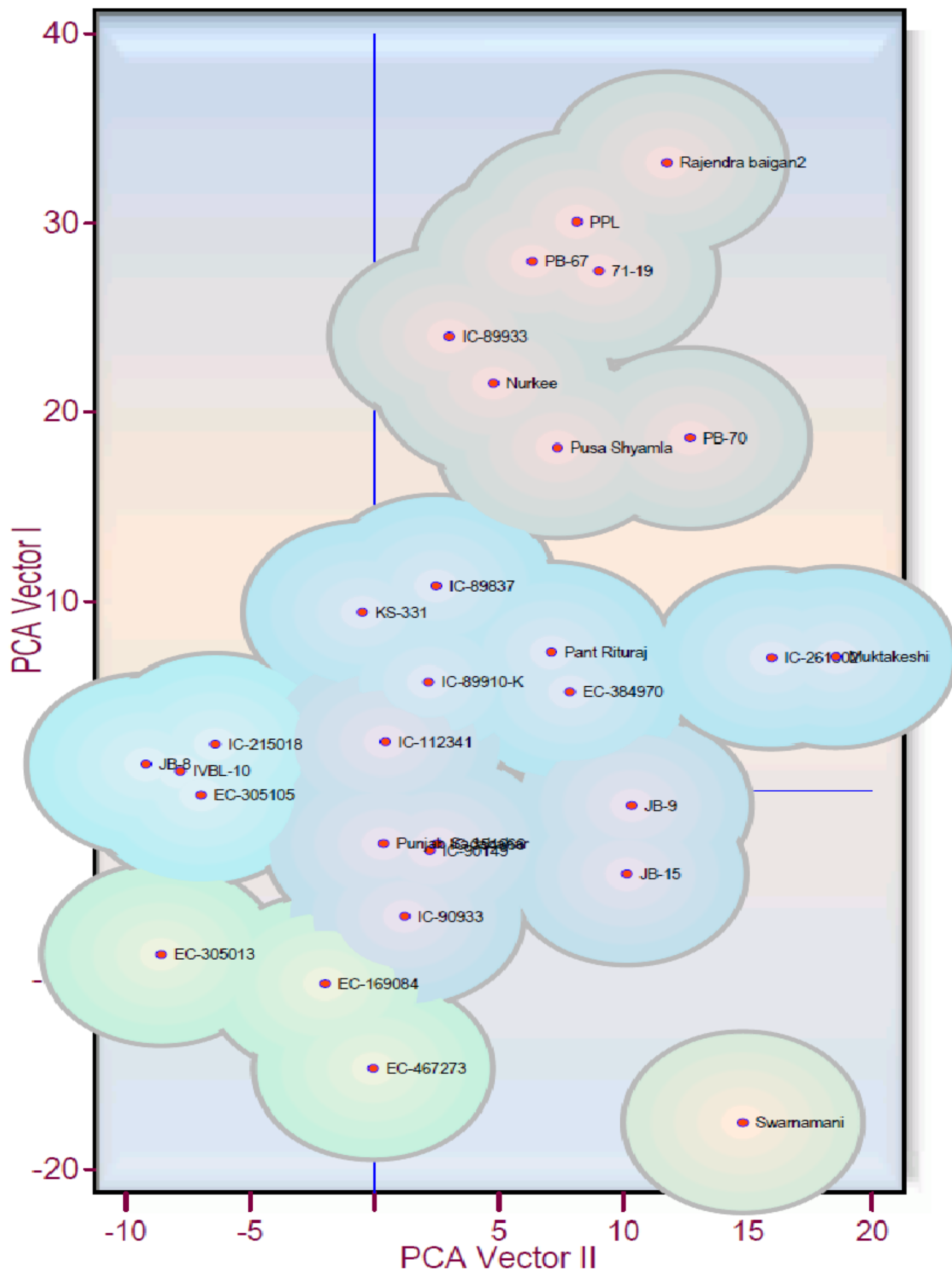


The third PC has positive association with fruit length, fruit weight, number of fruits per plant, while negative association with days to $50 \%$ flowering, days to $1^{\text {st }}$ harvest, fruit set $\%$ $\&$ test weight.

The fourth PC has positive association with days to $50 \%$ flowering and plant spread while negative association with fruit yield/plant, fruit set $\%$ and fruit weight. The fifth PC has positive association with petiole length while negative association with plant spread and test weight.

The traits of brinjal that demonstrated positive association with PCs have major role in genetic diversity analysis and explaining total genetic variation are in agreement with findings of Kundu et al., (2012). For future experiment, traits contributing maximum to genetic diversity such as days to $1^{\text {st }}$ flowering, days to $50 \%$ flowering and fruit set $\%$ should be given top priority as selection parameters and diverse genotypes identified in the present study may be utilized for attempting heterotic cross combination and developing hybrid varieties.

The results suggest a possibility for obtaining greater variation in the segregating generations derived from the hybridization of EC-467273 (Cluster IV) with 71-19, Rajendra Baigan-2, Pusa purple long (Cluster V). JB15, Swarna Mani and Muktakeshi (Cluster II) with 71-19, Rajendra Baigan-2, Pusa purple long (Cluster V) and EC-467273 (Cluster IV) with IC-89933, Pant Rituraj, Pusa Shyamla and PB-70 (Cluster VI) because of maximum genetic distance of these combinations. High cluster mean for most of the yield contributing traits coupled with inter cluster distance indicate the possibility of obtaining high heterotic vigour and selection of superior segregants by inter crossing genotypes from these clusters as reported by Mehta et al., (2004).

\section{References}

Arunachalum, V. 1984. Genetic distance in plant breeding. Indian Journal of Genetics. 41: 23-27.

Chandrasekhar, K.; Ashok, P. and Sasikala, K. 2012. Studies on heritability and multivariate analysis in brinjal (Solanum melongena L.). Vegetable crops Research Bulletin. 76: 79-88.

Das. S.; Mandal, A. B. and Hazra, P. 2010. Genetic diversity in brinjal genotypes under eastern Indian conditions. Indian Journal of Horticulture. 67: 166-169.

Goloni, I. J.; Pandya, H.M.; Mehta, D. R. and Purohit, V. L. 2007. A study on genetic diversity and genetic variability in brinjal (Solanum melongena L.). Agriculture Science Digest. 27(1): 2225.

Houshna, B. N. 2009. Morphological diversity studies in brinjal (Solanum melongena L.) and their related species. CBM Master's thesis. 57: 3-4.

Kundu, B.C., Hossain, M.M., Khaleque Mian, M.A. and Mian, I.H. 2012. Multivariate analysis in bitter gourd (Momordica charantia L.). J. Asiatic Soc. Bangladesh Sci. 38: 125-34.

Kundu, B.C., Hossain, M.M., Khaleque Mian, M.A. and Mian, I.H. 2012. Multivariate analysis in bitter gourd (Momordica charantia L.). J. Asiatic Soc. Bangladesh Sci. 38: 125-34.

Mahalanobis, P. C. 1928. A statistical study at Chinese head measurement. Journal of Asiatic Society of Bengal. 25: 301-307

Mehta, D. R., Golani, I. J.; Pandya, H.M.; Patel, R. K. and Naliyadhara, M. V. 2004. Genetic diversity in brinjal (Solanum melongena L.). Vegetable Science. 31: 142-45.

Mohanty, B. K. and Prusuti, A. M. 2001. Diversity studies in brinjal (Solanum melongena L.). Agriculture Science Digest. 21 (1): 17-20. 
Muniappan, S.; Saravanan, K. and Ramya, B. 2010. Studies on Genetic Divergence and Variability for Certain Economic Characters in Eggplant (Solanum Melongena L.). Electronic Journal of Plant Breeding. 1 (4): 462-465.

Munshi, A. D.; Kumar, Ravindra \& Rathi, Saurabh 2011. Breeding potential of brinjal genotypes using $\mathrm{D}^{2}$ analysis. Indian Journal of Horticulture. 68 (3): 328-331.

Prabakaran, S. 2010. Evaluation of local types of brinjal (Solanum melongena L.). M.Sc., (Hort.) Thesis, Agricultural College and Research Institute, TNAU, Madurai.

Samaik, D. A. and Verma, D. P. 1999. Correlation studies in brinjal (Solanum melongena L.) Advance Horticulture. 7: 91-94.

Sharma, A. and Maurya, I. B. 2004. Genetic divergence in brinjal (Solanum melongana L.). Orissa journal of Horticulture. 32(2): 22.25.
Singh, Jagtar; Kaur, Amandeep and Thakur, J. C. 2006. Studies on genetic divergence in brinjal. Research journal of Punjab agricultural University.43 (3):185-87.

Tambe, T. B.; Rane, D. A. and Kale, P. N. 1993. Diversity studies in brinjal (Solanum melongena L.). Maharashtra Journal of Horticulture. 7: 81-87.

Timmapur, P. H. 2007. Heterosis and combining ability studies in brinjal (Solanum melongena L.) M. Sc. Ag Thesis, Submitted to U. A. S. Dharwad, pp: 8-9.

Ward, J.H. Jr. 1963. Hierarchical grouping to optimize an objective function. Journal of American Statistics Association. 58: 236-44.

Yadav, D. S.; Prasad, A. and Singh, N. D. 1996. Genetic divergence for fruit yield and its components in brinjal (Solanum melongena L.). Annual Agricultural Research. 17: 265-71.

\section{How to cite this article:}

Neetu Nand, Anupam Adarsh, Amit Kumar, S. Akhtar, Randhir Kumar and Pankaj Kumar Ray. 2018. Morphological Characterization of Different Genotype of Brinjal (Solanum melongena). Int.J.Curr.Microbiol.App.Sci. 7(01): 2218-2226. doi: https://doi.org/10.20546/ijcmas.2018.701.267 